\title{
Stenotrophomonas rhizophila sp. nov., a novel plant-associated bacterium with antifungal properties
}

Institut für Molekulare

Physiologie und

Biotechnologie/

Mikrobiologie,

Fachbereich

Biowissenschaften der

Universität Rostock, Albert-

Einstein-Straße 3, D-18051

Rostock, Germany

\author{
Arite Wolf, Antje Fritze, Martin Hagemann and Gabriele Berg \\ Author for correspondence: Gabriele Berg. Tel: +49 381 4986154: Fax: +49 3814986152. \\ e-mail: gabriele.berg@biologie.uni-rostock.de
}

\begin{abstract}
A polyphasic taxonomic study was performed on 16 Stenotrophomonas strains from environmental and clinical sources. A group of three plant-associated isolates were shown to be phenotypically different from the other strains. This group formed a separate physiological cluster (B1) with $42 \%$ heterogeneity to the other isolates. The defining characteristics of the new species were as follows: growth at $4{ }^{\circ} \mathrm{C}$ and the absence of growth at $40{ }^{\circ} \mathrm{C}$; the utilization of xylose as a carbon source; lower osmolytic tolerance $(<4.5 \% \mathrm{NaCl}, \mathrm{w} / \mathrm{v})$, although the isolates can produce trehalose and glucosylglycerol as osmoprotective substances; the absence of lipase and $\beta$-glucosidase production; and antifungal activity against plant-pathogenic fungi. The wholecell fatty acid profile of this group was different and characterized by the main fatty acids iso- $C_{15: 0}$ and anteiso- $C_{15: 0}$. Numerical analysis of the fatty acid profiles of the strains examined supports the differentiation of the physiological B1 group. By 165 rDNA analysis, three clusters were distinguished. The three strains of the B1 group formed a separate environmental cluster (E1). They showed a mean similarity of $99.5 \%$ within the cluster, and differed from strains of a second environmental cluster (E2) by $2.2 \%$ and from the clinical cluster (C) by about 3.0\%. DNA-DNA hybridization data supported the taxonomic differentiation. All results led to the proposal of a new species, Stenotrophomonas rhizophila sp. nov., with strain e-p10'

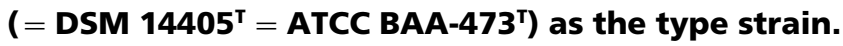

Keywords: Stenotrophomonas rhizophila sp. nov., plant-associated, antifungal, osmolytes, $16 \mathrm{~S}$ rDNA

\section{INTRODUCTION}

The genus Stenotrophomonas is phylogenetically placed in the $\gamma$-subclass of the Proteobacteria (Moore et al., 1997). The Stenotrophomonas genus was described with the species Stenotrophomonas maltophilia (Palleroni \& Bradbury, 1993), previously called Pseudomonas maltophilia (Hugh \& Ryschenko, 1961) and later changed to Xanthomonas maltophilia (Swings et al., 1983). Recently, Drancourt et al. (1997) proposed a new species; Stenotrophomonas africana, which is biochemically identical to $S$. maltophilia except for its

Abbreviation: DGGE, denaturing-gradient gel electrophoresis.

The EMBL accession number for the $16 \mathrm{~S}$ rDNA sequence of the isolate e$\mathrm{p} 10^{\top}$ is AJ293463. ability to assimilate cis-aconitate. Genotypic analysis, however, revealed only $35 \%$ DNA homology between the two species. Finkmann et al. (2000) characterized Stenotrophomonas strains with an unusual denitrification reaction as new species Stenotrophomonas nitritireducens.

Stenotrophomonas species have an important ecological role in the element cycle in nature (Ikemoto et al., 1980). The biotechnological importance of S. maltophilia is partly due to its potential plant growthpromoting effects and applications in the biological control of fungal diseases in plants (Berg et al., 1994; Kobayashi et al., 1995; Nakayama et al., 1999). Recent interest has also focused on the use of the species in decontamination of soil (bioremediation) because of its capacity to degrade xenobiotic compounds (Binks 
et al., 1995). In the last decade, S. maltophilia has also become important as a nosocomial multidrug-resistant pathogen associated with significant case/fatality ratios in certain patient populations, particularly in those who are severely debilitated or immunosuppressed (for a review, see Denton \& Kerr, 1998). Stenotrophomonas africana is also associated with human infections (Drancourt et al., 1997). Nothing is known about the pathogenic potential of the $S$. nitritireducens strains for humans or plants.

S. maltophilia was found in a wide variety of environments and geographical regions, and occupies ecological niches both inside and outside hospitals (Denton \& Kerr, 1998). S. maltophilia has been isolated not only from typical environments such as the rhizospheres of various plants (Juhnke \& Des Jardins, 1989; Berg et al., 1996) and from aquatic habitats (Minkwitz \& Berg, 2001), but also from the extreme environment of a soda lake and from the faeces of an arthropod (Denton \& Kerr, 1998). The variety of isolation sources has attracted scientific investigations concerning the epidemiology and differentiation of the strains. A certain heterogeneity in the physiological parameters has already been shown by Swings et al. (1983), Van den Mooter \& Swings (1990) and also by Palleroni \& Bradbury (1993) in the type description of $S$. maltophilia. Heterogeneity has been confirmed by genotypic studies (Gerner-Smidt et al., 1995; Chatelut et al., 1995; Nesme et al., 1995; Hauben et al., 1999; Berg et al., 1999). From the 16S rDNA sequencing analysis, $50 \mathrm{~S}$. maltophilia isolates could be separated into three genomovars: two comprised isolates (especially rhizosphere isolates) originating from the environment, and one comprised clinical and aquatic strains (Minkwitz \& Berg, 2001).

In this study, we characterized the molecular and physiological attributes of clinical and environmental S. maltophilia isolates, and defined isolates of one biovar and genomovar as a new species, Stenotrophomonas rhizophila sp. nov.

\section{METHODS}

Isolates and reference strains. A total of 16 clinical and environmental isolates of Stenotrophomonas were investigated (Table 1). The clinical strains were isolated in the Rigshospitalet, Copenhagen, Denmark, from various sites (tracheal aspirates, sputa, blood, throat, wounds, skin, ulcers, drainage fluids and aspirates, catheters, urine, etc.; Gerner-Smidt et al., 1995). S. maltophilia DSM 50170 ${ }^{\mathrm{T}}(=$ ATCC $13637^{\mathrm{T}}$, a type strain isolated from the pleural fluid of a patient with oral carcinoma; Hugh \& Ryschenko, 1961), S. nitritireducens DSM $12575^{\mathrm{T}}$ (a type strain isolated from an ammonia-supplied biofilter; Finkmann et al., 2000) and Xanthomonas campestris DSM $3586^{\mathrm{T}}$ were used as reference strains. All S. maltophilia isolates were identified using the API system (BioMérieux) and the Biolog identification system (Biolog) as S. maltophilia (Berg et al., 1999). Unless otherwise stated, isolates were routinely grown in nutrient broth 2 (Sifin) and stored in broth containing $15 \%$ glycerol at $-70^{\circ} \mathrm{C}$.
Physiological tests. The ability to use various sugars and derivatives was tested by using the API 50C system (bioMérieux). The cells were suspended in AUX-medium according to the manufacturer's manual, and were added to 50 different carbon sources. The ability to grow at $30^{\circ} \mathrm{C}$ was judged visually from the turbidity of the cultures. Significant reactions, i.e. those showing differences in carbon-source utilization between the strains, were repeated in $50 \mathrm{ml} \mathrm{MM} 8$ medium at 180 r.p.m. and $30^{\circ} \mathrm{C}$. The ability to grow at 4,37 and $41^{\circ} \mathrm{C}$ was tested in Luria-Bertani medium. Growth at various salinities was investigated at $30^{\circ} \mathrm{C}$ in $5 \mathrm{ml}$ medium according to Palleroni \& Doudoroff (1972), with the addition of $3 \cdot 0,4 \cdot 0,4 \cdot 5,5 \cdot 0,5 \cdot 5$ and $6 \cdot 0 \% \mathrm{NaCl}(\mathrm{w} / \mathrm{v})$. In all cases, the optical density was measured at $600 \mathrm{~nm}$. For analysing the production of osmolytes, isolates were grown in the medium suggested by Palleroni \& Doudoroff (1972), supplemented with DL-methionine $\left(40 \mathrm{mg} \mathrm{l}^{-1}\right)$ and $\mathrm{NaCl}$ to obtain the indicated salinity. Cells were harvested by centrifugation and washed with growth medium in which all organic constituents had been replaced by $\mathrm{NaCl}$. Low-molecularmass compounds were extracted with $80 \%$ ethanol, and the extracts were desalted using ion-exchange resins. HPLC analysis was performed according to Mikkat et al. (2000). Antifungal activity was determined by using a dual-culture in vitro assay on Waksman agar containing $5 \mathrm{~g}$ proteosepeptone (Merck), $10 \mathrm{~g}$ glucose (Merck), $3 \mathrm{~g}$ meat extract (Chemex), $5 \mathrm{~g} \mathrm{NaCl}$ (Merck), $20 \mathrm{~g}$ agar (Difco) and distilled water (to 11 ), $\mathrm{pH} 6.8$. Zones of inhibition were measured after 5 days incubation at $20^{\circ} \mathrm{C}$ according to Minkwitz \& Berg (2001). All strains were tested in three independent replicates. Fungi used in this bioassay include Rhizoctonia solani, Verticillium dahliae, Sclerotinia sclerotiorum and Candida albicans. The fungal strain R. solani DSM 63010 was obtained from the Deutsche Sammlung für Mikroorganismen und Zellkulturen $\mathrm{GmbH}$ (Braunschweig, Germany). The other pathogenic fungi were obtained from the strain collection of the University of Rostock (Department of Microbiology). These fungi were routinely grown on Sabouraud medium (Gibco) and stored in broth containing $15 \%$ glycerol at $-70{ }^{\circ} \mathrm{C}$.

Fatty acid analysis. Isolates were cultivated for 3 days on trypticase soy agar at $25^{\circ} \mathrm{C}$. Harvesting, saponification, methylation and extraction of fatty acid methyl esters were performed according to Sasser (1990). Identification of the fatty acid methyl esters was performed by GC-MS as described by McInroy \& Kloepper (1995). Data on the fatty acids from $S$. nitritireducens strains were analysed by Finkmann et al. (2000).

$16 S$ rDNA sequencing. Bacterial DNA was prepared by following the protocol of Andersen \& McKay (1983), modified for genomic DNA. 16S rDNA was amplified using the prokaryote-specific forward primer 16F27 and reverse primer 16R1525 (Lane, 1991) as described by Minkwitz \& Berg (2001). For amplification, the PCR SuperMix High Fidelity (Gibco), with a mixture of Taq DNA polymerase and DNA polymerase from Pyrococcus sp. GB-D, was used. The amplified bands were eluted from the agarose and purified by using the GFX PCR DNA and Gel band purification kit (Amersham Pharmacia Biotech). The 16S rDNA fragments were cloned in the pGEM-T vector (Promega) and transformed into Escherichia coli. Plasmid isolation was carried out using the GFX Micro Plasmid Prep kit (Amersham Pharmacia Biotech), and sequencing reactions were done with the SequiTherm EXCEL II Long Read DNA Sequencing kit-LC (BIOzym), both according to the manufacturer's instruction. The gel run was performed 
Table 1. Bacterial strains investigated in this study, their origins, relevant references, and clustering by $165 \mathrm{rDNA}$ sequencing and fatty acid methyl esters

\begin{tabular}{|c|c|c|c|c|c|c|}
\hline Strain & $\begin{array}{l}\text { Currently valid } \\
\text { or proposed name }\end{array}$ & Origin & Reference & $\begin{array}{l}\text { Cluster } \\
\text { biovar }\end{array}$ & $\begin{array}{c}\text { Cluster } \\
\text { fatty acid }\end{array}$ & $\begin{array}{c}\text { Cluster } \\
\text { genomovar }\end{array}$ \\
\hline e-p10 & S. rhizophila & Rhizosphere of rape; Rostock, 1993 & Minkwitz \& Berg (2000) & B1 & $\mathrm{F} 1$ & E1 \\
\hline e-p14 & S. rhizophila & Rhizosphere of potato; Lüsewitz, 1996 & Minkwitz \& Berg (2000) & B1 & $\mathrm{F} 1$ & E1 \\
\hline e-p17 & S. rhizophila & Geocaulosphere of potato; Lüsewitz, 1996 & Minkwitz \& Berg (2000) & B1 & $\mathrm{F} 1$ & E1 \\
\hline e-p3 & S. maltophilia & Rhizosphere of rape; Poel, 1989 & Minkwitz \& Berg (2000) & B2 & $\mathrm{F} 2$ & E2 \\
\hline e-p19 & S. maltophilia & Geocaulosphere of rape; Lüsewitz, 1996 & Minkwitz \& Berg (2000) & B2 & $\mathrm{F} 2$ & E2 \\
\hline e-p20 & S. maltophilia & Rhizosphere of potato; Braunschweig, 1998 & Berg et al. (2001) & B2 & $\mathrm{F} 2$ & E2 \\
\hline $\mathrm{c} 5$ & S. maltophilia & Human; Copenhagen, 1995 & Gerner Smidt et al. (1995) & B4 & $\mathrm{F} 2$ & $\mathrm{C}$ \\
\hline c6 & S. maltophilia & Human; Copenhagen, 1995 & Gerner Smidt et al. (1995) & B4 & F3 & $\mathrm{C}$ \\
\hline $\mathrm{c} 20$ & S. maltophilia & Human; Copenhagen, 1995 & Gerner Smidt et al. (1995) & B4 & $\mathrm{F} 2$ & $\mathrm{C}$ \\
\hline e-al & S. maltophilia & Brackish water; Zingst, 1996 & Minkwitz \& Berg (2000) & B5 & $\mathrm{F} 4$ & $\mathrm{C}$ \\
\hline e-a22 & S. maltophilia & Sewage; Braunschweig, 1999 & Minkwitz \& Berg (2000) & B4 & $\mathrm{F} 4$ & $\mathrm{C}$ \\
\hline e-a21 & S. maltophilia & Sewage; Braunschweig, 1999 & Minkwitz \& Berg (2000) & B4 & $\mathrm{F} 4$ & $\mathrm{C}$ \\
\hline e-a23 & S. maltophilia & Eye-care solution; Munich, 1999 & Baader (1999) & B4 & F4 & $\mathrm{C}$ \\
\hline e-p13 & S. maltophilia & Rhizosphere of rape; Rostock, 1995 & Minkwitz \& Berg (2000) & B3 & $\mathrm{F} 2$ & $\mathrm{C}$ \\
\hline DSM $50170^{\mathrm{T}}$ & S. maltophilia & Human; 1961 & Hugh (1961) & B4 & $\mathrm{ND}$ & $\mathrm{C}$ \\
\hline DSM $12575^{\mathrm{T}}$ & S. nitritireducens & Ammonia-supplied biofilters & Finkmann et al. (2000) & & & \\
\hline DSM $3586^{\mathrm{T}}$ & X. campestris & Brassica oleracea & Skerman et al. (1980) & & & \\
\hline
\end{tabular}

using a LI-COR automated DNA sequencing machine (MWG Biotech). The sequence data were collected and analysed by the MWG-Biotech software package BaseImagIR, version 4.1. The $16 \mathrm{~S}$ rDNA sequence of each strain was aligned with reference $16 \mathrm{~S}$ rRNA gene sequences from the GenBank, EMBL and DBJ databases by using the BLAST algorithm (Altschul et al., 1997). Sequence similarities were calculated for the complete sequence by using unambiguously determined nucleotide positions with the sequence alignment program ALIGN PLUS, version 2.0 (Scientific and Educational Software). Distance and bootstrap analyses were performed with the ARB program (Ludwig \& Strunk; http://www.mikro.biologie.tu-muenchen.de), using the neighbour-joining method (Saitou \& Nei, 1987), maximum parsimony and maximum likelihood (Felsenstein, 1992).

Molecular typing by denaturing gradient gel electrophoresis. Total DNA was extracted from the bacterial pellet as described above. PCR amplification of the bacterial $16 \mathrm{~S}$ rDNA fragment was carried out using primers V3341F (5'CGC CCG CCG CGC GCG GCG GGC GGG GCG GGG GCA CGG GGG GCC TAC GGG AGG CAG CAG-3') and V3534R (5'-ATT ACC GCG GCT GCT GG-3') spanning the 16S rDNA from positions 341 to 534, including the V3 region. Separation of the PCR products was done by denaturing-gradient gel electrophoresis (DGGE) analysis as previously described (Heuer et al., 1997). The procedure was replicated three times.

DNA-DNA hybridization. DNA was isolated by chromatography on hydroxyapatite by the procedure of Cashion $e t$ al. (1977). DNA-DNA hybridization was carried out as described by De Ley et al. (1970), with the modifications described by Huss et al. (1983) and Escara \& Hutton (1980). Analysis was done using a Gilford System model 2600 spectrophotometer equipped with a Gilford model 2527-R thermoprogrammer and plotter. Renaturation rates were computed with the TRANSFER : BAS program of Jahnke (1992).

Statistical data analysis. Interisolate relationships were measured by the Euclidian metric, unweighted pair group arithmetic average-linkage algorithm method using the program STATISTICA (StatSoft). Thus, physiological data and fatty acid methyl ester data were converted to a binary code.

\section{RESULTS}

\section{Physiological tests}

A total of 16 Stenotrophomonas strains from different sources (listed in Table 1) were characterized by their physiological profiles including the following: growth at different temperatures and on different carbon sources; osmotolerance and production of osmoprotective substances; and enzymic and antifungal activity. These profiles were compared using numerical methods, and the resultant dendrogram based on percentage similarity between the isolates showed the diversity. Three different clusters (B1, B2 and B4) and two single strains (e-p13 = B3 and e-a $1=\mathrm{B} 5)$ could be separated on the basis of $85 \%$ similarity (Table 1 ). Three plant-associated isolates (e-p10 ${ }^{\mathrm{T}}$, e-p14 and ep17) formed the separate cluster B1. They showed $42 \%$ heterogeneity with respect to the other Stenotrophomonas isolates. Two other clusters (B2 and B3) were formed by plant-associated isolates with $20 \%$ heterogeneity to other B4-group strains. Cluster B4 contained human-associated strains as well as aquatic and sewage strains.

Table 2 shows a number of physiological characteristics that separate the B1-group isolates from other $S$. maltophilia isolates. Differences were found in the growth at different temperatures. While isolates of the B1 group grew at $4{ }^{\circ} \mathrm{C}$ but not at $40^{\circ} \mathrm{C}$, in contrast, the majority of $S$. maltophilia isolates grew at $40^{\circ} \mathrm{C}$ but not at $4{ }^{\circ} \mathrm{C}$. Furthermore, the B1 strains demonstrated the ability to use xylose as a carbon source, whereas the majority of $S$. maltophilia isolates were unable to use xylose. Other differences between $\mathrm{B} 1$ isolates and $S$. maltophilia included tolerance to $5 \% \mathrm{NaCl}(\mathrm{w} / \mathrm{v})$, and the production of osmoprotective substances. Most $S$. maltophilia isolates were able to tolerate this high $(5 \% \mathrm{NaCl})$ salinity even though they produced only one osmoprotective substance (trehalose). The growth of the three isolates of the B1 group was inhibited by $5 \% \mathrm{NaCl}(\mathrm{w} / \mathrm{v})$. However, at a salinity of 
Table 2. Physiological characteristics that differentiate $S$. rhizophila from S. maltophilia

\begin{tabular}{|c|c|c|}
\hline \multirow[t]{2}{*}{ Character } & \multicolumn{2}{|c|}{ Positive strains (\%) } \\
\hline & $\begin{array}{l}\text { B1 isolates } \\
(\text { S. rhizophila }) \\
\quad(n=3)\end{array}$ & $\begin{array}{l}\text { S. maltophilia } \\
(n=13)\end{array}$ \\
\hline \multicolumn{3}{|l|}{ Growth at: } \\
\hline $4^{\circ} \mathrm{C}$ & 100 & 16 \\
\hline $37^{\circ} \mathrm{C}$ & 100 & 100 \\
\hline $41^{\circ} \mathrm{C}$ & 0 & 72 \\
\hline Growth on xylose & 100 & 18 \\
\hline $\begin{array}{l}\text { Growth in the presence } \\
\text { of } 5 \% \mathrm{NaCl}\end{array}$ & 0 & 100 \\
\hline \multicolumn{3}{|l|}{ Production of osmolytes } \\
\hline Trehalose & 100 & 100 \\
\hline Glucosylglycerol & 100 & 0 \\
\hline \multicolumn{3}{|l|}{$\begin{array}{l}\text { Production of specific } \\
\text { enzymes }\end{array}$} \\
\hline Lipase & 0 & 82 \\
\hline$\beta$-Glucosidase & 0 & 100 \\
\hline \multicolumn{3}{|l|}{$\begin{array}{l}\text { Antifungal activity } \\
\text { towards: }\end{array}$} \\
\hline Candida albicans & 100 & 0 \\
\hline Rhizoctonia solani & 100 & 0 \\
\hline Sclerotinia sclerotiorum & 100 & 0 \\
\hline Verticillium dahliae & 100 & 0 \\
\hline
\end{tabular}

Table 3. Physiological characteristics of the Stenotrophomonas and $X$. campestris isolates and reference strains

Strains: 1, S. maltophilia DSM $50170^{\mathrm{T}} ; 2, X$. campestris DSM $3586^{\mathrm{T}}$; 3, S. nitritireducens DSM $12575^{\mathrm{T}} ; 4$, S. rhizophilia $(n=3)$.

\begin{tabular}{|lcccc|}
\hline Characteristic & $\mathbf{1}$ & $\mathbf{2}$ & $\mathbf{3}$ & $\mathbf{4}$ \\
\hline Nitrate reduction to nitrite & + & - & - & 100 \\
Aesculin hydrolysis & + & - & - & 100 \\
Lecithinase & + & + & - & 0 \\
Growth at: & & & & \\
$4{ }^{\circ} \mathrm{C}$ & - & + & - & 100 \\
$37^{\circ} \mathrm{C}$ & + & - & + & 100 \\
Growth in the presence of: & & & & \\
Erythromycin & + & + & - & 67 \\
Kanamycin & - & - & - & 0 \\
Gentamicin & + & + & & 100 \\
Tetracycline & - & - & - & 0 \\
Novobiocin & + & - & - & 67 \\
$4 \%$ NaCl & + & - & & 100 \\
Production of xanthomonadins & - & + & - & - \\
Plant pathogenicity & - & + & - & - \\
\hline
\end{tabular}

$3 \%$, the strains of B1 group produced two different osmolytes: trehalose and glucosylglycerol. At salinities higher than $5 \% \mathrm{NaCl}(\mathrm{w} / \mathrm{v})$, no growth could be detected for all strains tested (data not shown). Using APIZym, differences in enzyme production were found between both groups. Lipase and $\beta$-glucosidase activity was found for most $S$. maltophilia isolates but was absent among the B1 group strains. Antifungal activity against phytopathogenic and human-pathogenic fungi was tested using dual-culture assay. All of the B1 isolates possessed antagonistic activity, whereas the other isolates gave a negative reaction. Physiological properties of the strains of B1 group in comparison with other Stenotrophomonas and X. campestris strains are shown in Table 3.

\section{Fatty acid analysis}

By the analysis of fatty acid methyl esters of the total cellular fatty acids, significant differences between the isolates could be detected. The fatty acid profiles were compared by using numerical methods; the resultant grouping, founded on the basis of $80 \%$ similarity, is shown in Table 1. Three different clusters (F1, F2 and F4) and one single strain (c6 = F3) could be detected. Cluster F1 comprised the same isolates as the physiological $\mathrm{B} 1$ group. Iso-branched $\mathrm{C}_{15: 0}$ was the major fatty acid component of the B1 group and constituted $26-27 \%$ of the total content. Other characteristic fatty acids were iso-branched: $\mathrm{C}_{14: 0}(2-3 \%), \mathrm{C}_{17: 1} \omega_{9 c}$ $(5-6 \%)$ and $\mathrm{C}_{17: 1} \omega_{8 c}(0 \cdot 5-0.7 \%)$. For the F1 cluster, the absence of the cyclic fatty acid $\mathrm{C}_{17: 0}$ (cyclopropane), which is typical for $S$. maltophilia, was a defining characteristic. Groups F2 and F4 contained plant- and human-associated isolates. The human isolate c6 formed its own group and was characterized by a very specific fatty acid profile. Detailed results on the fatty acid compositions of the isolates are available as supplementary data in IJSEM Online (http://ijs. sgmjournals.org).

\section{$16 \mathrm{~S}$ rDNA sequencing and phylogenetic analyses}

By using primers annealing at positions 27 and 1525 , respectively, of the $16 \mathrm{~S}$ rDNA, nearly the complete gene could be amplified, cloned and finally sequenced. About 1500 bases were determined, corresponding to $99 \%$ of the gene. By cloning the amplified fragments and using plasmid- and prokaryote-specific primers, exact sequences of 700 to $800 \mathrm{bp}$ could be obtained. Each gene sequence was confirmed by determining contiguous overlapping sequences in both directions.

A similarity of $98-99 \%$ meant that the strains could be determined as $S$. maltophilia by the BLAST algorithm. The most similar were S. maltophilia strains LMG $958^{\mathrm{T}}$ and LMG 957 (with respect to the clinical strains) and LMG 10857 (with respect to the environmental E1 strains).

Fig. 1 shows the inferred phylogenetic relationship between the investigated strains, S. maltophilia DSM $50170^{\mathrm{T}}$, S. nitridireducens DSM $12575^{\mathrm{T}}$, S. africana and $X$. campestris DSM $3586^{\mathrm{T}}$. Three genetic clusters could be distinguished among the $S$. maltophilia isolates. Two of them, E1 and E2, consist of only 


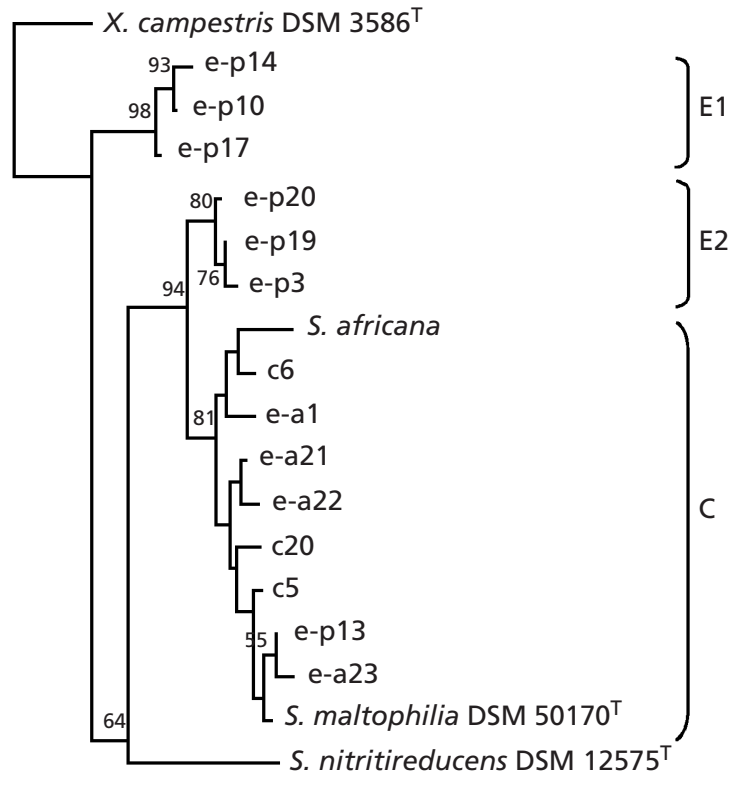

0.01

Fig. 1. Phylogenetic tree obtained by neighbour joining without the filter distance matrix, using the ARB program. The reliability of branching was assessed using bootstrapping analysis. Only values of more than $50 \%$ are shown. $X$. campestris DSM $3586^{\top}$ is used as an outgroup for showing the root of the tree. Parsimony and maximum-likelihood estimations, using the PHYLIP program, resulted in the same tree, reflecting the differentiation of the E1 cluster as a separate species. Bar, $1 \%$ sequence difference.

plant-associated strains. The third cluster (C) included clinical and aquatic strains with a strong relationship to strain DSM $50170^{\mathrm{T}}$, as well as one plant-associated strain, e-p13. By all treeing methods, strains e-p $10^{\mathrm{T}}$, ep14 and e-p17 of the physiological B1 group formed the separate cluster E1 with about $99.5 \%$ similarity within the cluster and a difference of $2.5 \%$ from the clinical cluster, whereas the strains of the E2 cluster (physiological B2 cluster) showed a mean difference of only $1 \%$ from the clinical cluster and $1.5 \%$ from cluster E1. The small differences between clusters E2 and $\mathrm{C}$ seems not to point to the differentiation of a new species. The results emphasized the separate position of the E1 strains now named $S$. rhizophila. While $S$. africana clearly clustered into the C group, $S$. nitritireducens showed about 3\% difference from all analysed sequences. The similarities to $X$. campestris strain DSM $3586^{\mathrm{T}}$ were $96 \cdot 5,96.8$ and 97.4 for the clinical, E2 and E1 clusters, respectively.

The main variable regions were located near the $5^{\prime}$ end of the $16 \mathrm{~S}$ rDNA. Key sequences of the strains differentiated between the clinical and the environmental clusters as well as between the two environmental clusters. The most important area of difference is the V3 variable region (E. coli positions 447-487). Here, the clinical and cluster E2 strains were similar, whereas the cluster E1 strains showed the highest
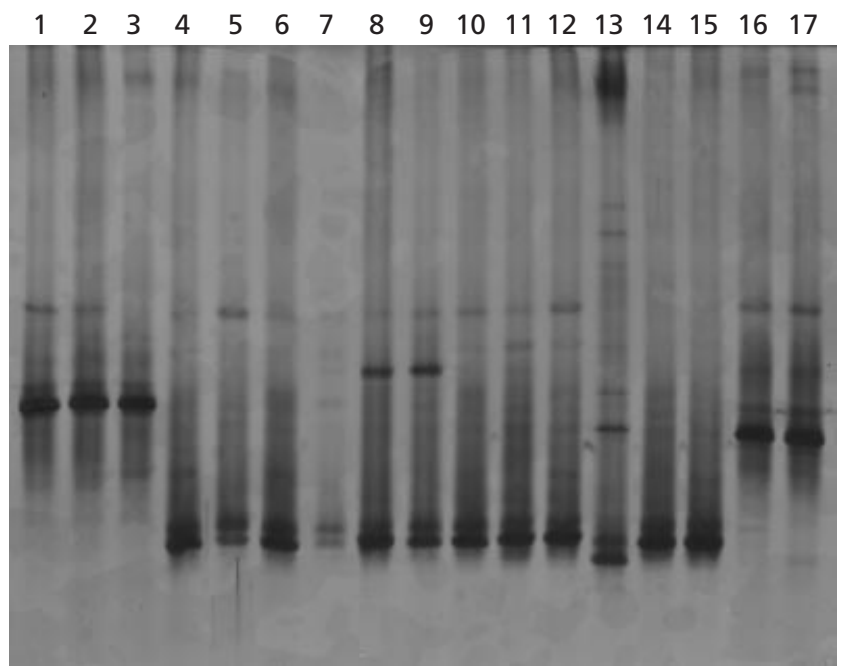

Fig. 2. DGGE profiles of the S. rhizophila isolates, S. maltophilia and reference organisms, based on their V3-16S rDNA sequence. Lanes: 1 , e-p $10^{\top} ; 2$, e-p14; 3, e-p17; 4, e-p3; 5, e-p19; 6 , e-p20; $7, c 5 ; 8, c 6 ; 9, c 20 ; 10$, e-a1; 11, e-a22; 12, e-a21; 13, e-a23; 14, e-p13; 15, S. maltophilia DSM 50170 $;$; 16, S. nitritireducens DSM $12575^{\top} ; 17, X$. campestris DSM $3586^{\top}$.

variability with nine base substitutions. This is reflected in the DGGE profiles of this region of the investigated and the reference strains (Fig. 2). It was possible to separate strains of E1 group from the other Stenotrophomonas strains according to their band positions on the DGGE gels. In the V8 variable region, which is regularly used for DGGE, only the cluster E1 strains showed divergent base compositions, and this was within four positions.

\section{DNA-DNA hybridization experiments}

The phylogenetic relationship between strain e-p $10^{\mathrm{T}}$ (the only representative of the E1 group) and the type strains of $S$. maltophilia and $S$. nitritireducens was resolved by DNA-DNA reassociation experiments. The DNA similarities were 48.1 and $52.3 \%$ (with $S$. maltophilia) and $30 \cdot 1 \%$ (with S. nitritireducens). These values clearly indicate that strains of the E1 group represent a separate species, i.e. S. rhizophila.

\section{DISCUSSION}

\section{Physiological aspects and fatty acid composition}

The strains investigated were clearly members of the genus Stenotrophomonas, as seen from the numerous biochemical properties studied. Although the properties showed a high degree of heterogeneity, investigations confirmed that the strains belong to $S$. maltophilia (Berg et al., 1999). We observed that plantassociated strains which belong to the physiological B1 group had the ability to grow at lower temperatures. As the environmental strains had a preference for lower temperatures, it is not surprising that they are able to survive in the rhizosphere (Sørensen, 1997). In 
contrast to the other $S$. maltophilia isolates investigated, only members of the B1 group were able to utilize xylose as a carbon source. Xylose is a substantial component of the plant root. The ability to metabolize xylose is an advantage for plant-associated bacteria. Many such bacteria, for example Pseudomonas putida, Pseudomonas fluorescens, Pseudomonas syringae and $X$. campestris, are able to use this carbon source for both symbiotic and pathogenic interactions.

Bacteria are able to adapt within a certain range of changes in external osmolarity by the accumulation of osmoprotective compounds. The Stenotrophomonas strains showed different ranges of osmotolerance. $S$. maltophilia isolates could grow well at $5 \% \mathrm{NaCl}$, whereas for members of the B1 group, $4.5 \%$ was the highest salinity allowing growth. Tolerance to high and changing salinities is important for adaptation in both microenvironments (the rhizosphere and the human body) (Miller \& Wood, 1996). All strains of Stenotrophomonas synthesized trehalose, but only strains of the B1 group accumulated glucosylglycerol as an additional substance. The composition of osmoprotective substances provided also valuable taxonomic information to characterize pseudomonads (Mikkat et al., 2000).

Differences between the B1 group and the other $S$. maltophilia strains were found in enzyme production. In contrast to $S$. maltophilia, the B1-group showed no lipolytic activity or $\beta$-glucosidase production. $S$. maltophilia strains were strongly lipolytic (Denton \& Kerr, 1998). The presence of glycoside hydrolases, e.g. $\beta$ glucosidases, is also typical for $S$. maltophilia and plant-pathogenic Xanthomonas strains (Van Zyl \& Steyn, 1992). The three strains of the B1 group showed remarkable antifungal activity against plant-pathogenic fungi. At present, S. maltophilia is not regarded as a plant-pathogenic bacterium; on the contrary, it is associated with human infections. In fact, interaction with eukaryotic cells is typical for the Stenotrophomonas-Xanthomonas group. The grouping according to the physiological parameters was confirmed by the data on the fatty acid compositions. The isolates of the physiological B1 group formed a separate cluster (F1) with regard to fatty acid composition.

On the basis of these significant characteristics, we propose the new species S. rhizophila. The defining characteristics of the new species are as follows: growth at $4{ }^{\circ} \mathrm{C}$ and the absence of growth at $40^{\circ} \mathrm{C}$; the utilization of xylose as a carbon source; lower osmotic tolerance $(<4.5 \% \mathrm{NaCl}, \mathrm{w} / \mathrm{v})$, although they can produce glucosylglycerol in addition to trehalose; the absence of lipase and $\beta$-glucosidase production; and antifungal activity.

\section{Analysis of the 16S rDNA sequence}

The pairwise comparison of all $16 \mathrm{~S}$ rDNA sequences resulted in three separate clusters corresponding well with the clustering obtained after analysis of physiological features. Two clusters with environmental rhizosphere isolates (E1 and E2) and one with clinical, aquatic and (one) environmental strains (C) were obtained. The aquatic strains were derived from a brackish lagoon (e-a1), sewage (e-a21, e-a22) and eyecare solution (e-a23). Since the brackish lagoon can be characterized as a prefilter basin of the Baltic Sea, with a high input of sewage from households and hospitals (Schlungbaum et al., 1994), and since the strains isolated from the eye-care solution caused endophthalmitis (Bader et al., 1999), classification of these strains as clinical can be concluded. Strain e-p13 represented an exception as it originated from the rhizosphere of oilseed rape. This complicates the exact differentiation between clinical and environmental isolates by $16 \mathrm{~S}$ rDNA sequence analysis, but illustrates the possibility that strains may be able to cross the clinical-environmental divide. Interestingly, strain ep13 was clustered according to its fatty acid profile into group F2 (comprising only plant-associated strains). According to the physiological data, the strain formed a separate cluster (B3), indicating its atypical behaviour

Upon analysing the sequence data in more detail, we noted that the cluster E1 strains differ in 32 bases $(2 \cdot 1 \%)$ when compared with the clinical isolates, most of the differences occurring in the V2, V3 and V8 variable regions. Twenty-three of these were similar to those of $X$. campestris strain DSM $3585^{\mathrm{T}}$. The separation of the E1 cluster from the other strains tested was emphasized by all the treeing methods used with high bootstrap values. The base changes can be considered as 'signature positions' and are characteristic for the cluster. The strains of cluster E2 differed from the clinical isolates in 13 bases $(0 \cdot 8 \%)$. Seven positions were the same as those of strains in cluster E1 and $X$. campestris DSM $3585^{\mathrm{T}}$. The clinical strains varied in 10 bases, corresponding to $0.6 \%$ of the whole 16S rRNA operon.

The V3 variable region was the only one likely to classify strains of cluster E1 from those of clusters E2 and $\mathrm{C}$ within a narrow range of nucleotides (Minkwitz $\&$ Berg, 2001). The environmental strains of E1 varied in nine independent positions in V3, which therefore makes this region suitable for oligonucleotide probe design (Amann et al., 1995). A larger part of this region has been used in DGGE (Muyzer et al., 1993). As shown in Fig. 2, with suitable primers we could differentiate between strains of cluster E1 and the human-associated and aquatic strains. At the V8 region, which is regularly used for DGGE analysis, the strains of cluster E1 differed in only four bases from the clinical, as well as from the E2, cluster strains. This difference has proved to be too small to allow differentiation by DGGE analysis (Berg et al., 1999).

Additionally, the E1 strains were different in two positions (989 and 1216) of the U6 universal region. Comparison of this with the secondary structure of the 16S rRNA molecule (Woese et al., 1983) indicated that these two positions are complementary and have no influence on the molecular structure. 


\section{Phylogenetic analysis}

The strains of cluster E1 showed significant differentiation when comparisons were made not only with the physiological profiles but also with the $16 \mathrm{~S}$ rDNA sequence data. On the basis of $16 \mathrm{~S}$ rDNA, Moore et al. (1997) mentioned a $3 \%$ difference between the genera Stenotrophomonas and Xanthomonas, which is equivalent to 45-68 nucleotide positions. Here, we obtained 44 nucleotide differences between strains $S$. maltophilia DSM $50170^{\mathrm{T}}$ and $X$. campestris DSM $3586^{\mathrm{T}}$, which is exactly $2.96 \%$. Normally, this level of sequence difference suggests strains of different species. If $3 \%$ is used as the 'yardstick' between the two genera Stenotrophomonas and Xanthomonas, and after the transfer of the high $16 \mathrm{~S}$ rDNA similarity values among various Xanthomonas species of 98.9-100\% (Hauben et al., 1997) to S. maltophilia, the isolates of cluster E1 must be regarded as a different species.

The bacterial species definition should be based on both DNA-DNA hybridization and 16S rDNA sequence analysis (Stackebrandt \& Goebel, 1994). In this study, the DNA-DNA hybridization resulted in strong differences between the representative strain of the B1 group (e-p $10^{\mathrm{T}}$ ) and the type strains of $S$. maltophilia and $S$. nitritireducens. According to Wayne et al. (1987), differences of more than $30 \%$ in DNA-DNA hybridization indicates a new species. Because of the clear physiological and phylogenetic clustering of the E1 strains, it did not appear to be necessary to do this analysis within these strains. On the basis of these results, we propose a new bacterial species, $S$. rhizophila.

\section{Description of Stenotrophomonas rhizophila sp. nov.}

Stenotrophomonas rhizophila (rhi.zo'phi.la. Gr. n. rhizo root; Gr. adj. philos loving; rhizophila root-loving).

Straight or slightly curved rods. Colonies are yellowish; the colour is not due to carotenoid pigments or to xanthomonadins. Growth takes place at $4-37^{\circ} \mathrm{C}$ but not at $40{ }^{\circ} \mathrm{C}$. Neither lipolytic nor $\beta$-glucosidase activity occurs. The strains use xylose as a carbon source. Strains are able to utilize (oxidize) the following carbon sources: dextrin, glycogen, Tween $80, N$-acetylD-galactosamine, $N$-acetyl-D-glucosamine, D-fructose, gentiobiose, $\alpha$-D-glucose, maltose, D-mannose, methyl $\beta$-D-glucoside, D-trehalose, turanose, methylpyruvate, mono-methyl succinate, acetic acid, cis-aconitic acid, citric acid, $\alpha$-hydroxy butyric acid, $\beta$-hydroxy butyric acid, $\gamma$-hydroxy butyric acid, $\alpha$-keto-butyric acid, $\alpha$ keto glutaric acid, DL-lactic acid, malonic acid, propionic acid, succinic acid, bromo succinic acid, succinamic acid, alaninamide, D-alanine, L-alanine, Lalanine, L-alanylgyline, L-asparagine, L-aspartic acid, L-glutamic acid, glycyl-L-aspartic acid, glycyl-L-glutamic acid, L-histidine, L-serine, L-threonine, DLcarnitine, urocanic acid, inosine and uridine. The predominant fatty acids are iso- $\mathrm{C}_{15: 0}$ and anteiso$\mathrm{C}_{15: 0}$. Growth occurs in the presence of $4.5 \% \mathrm{NaCl}$ but is inhibited at $5 \% \mathrm{NaCl}$ and above. Produces the osmoprotective substances trehalose and glucosylglycerol at $3 \% \mathrm{NaCl}$. Resistant to many antibiotics, e.g. penicillin, tobramycin, imipenem, and ceftazidime, but susceptible to chloramphenicol, kanamycin and trimethoprim/sulfamethoxazole. Strains were plantassociated and isolated from the rhizosphere of oilseed rape and from the the rhizosphere and geocaulsophere (tuber) of potato. Endophytic colonization was found. Antagonistic activity was shown against plantpathogenic fungi, e.g. Verticillium dahliae, Rhizoctonia solani, Sclerotinia sclerotiorum and the humanpathogenic fungus Candida albicans. They are not active against bacteria. The type strain is Stenotrophomonas rhizophila e-p $10^{\mathrm{T}}\left(=\mathrm{DSM} 14405^{\mathrm{T}}=\mathrm{ATCC}\right.$ BAA $-473^{\mathrm{T}}$ ).

\section{ACKNOWLEDGEMENTS}

We thank Hella Goschke for valuable technical assistance, and Lutz Bader (Munich), Britta Bruun (Copenhagen), Petra Marten and Jana Lottmann (Rostock), Kornelia Smalla (Braunschweig) and Matthias Scholz (Leipzig) for providing the Stenotrophomonas strains. We thank Johannes Hallmann and Anne Faupel (Bonn) for analysing fatty acid methyl ester data, Anja Roder (Rostock) for the determination of osmolytic substances, Günter Jost (Rostock) for constructing the tree, Christian Berg (Rostock) and Eckehard Jäger (Halle/Saale) for taxonomic help, and Jürgen Schumacher (Braunschweig) for DNA-DNA hybridization analysis. This study was supported by the Deutsche Forschungsgemeinschaft and the Fonds der Chemischen Industrie.

\section{REFERENCES}

Altschul, S. F., Madden, T. L., Schaffer, A. A., Zhang, J., Zhang, Z., Miller, W. \& Lipman, D. J. (1997). Gapped BLAST and PSI-BLAST: a new generation of protein database search programs. Nucleic Acids Res 25, 3389-3402.

Amann, R., Ludwig, W. \& Schleifer, K.-H. (1995). Phylogenetic identification and in situ detection of individual microbial cells without cultivation. Microbiol Rev 59, 143-169.

Anderson, D. G. \& McKay, L. L. (1983). Simple and rapid method for isolating large plasmid DNA from lactic streptococci. Appl Environ Microbiol 46, 549-559.

Bader, L., Riedel, K. G., Maydl, G., Ritter, E., Wirsing von König, C., Meroe, A., Billing, J., Hensel, G. \& Heesemann, J. (1999). Postoperative Stenotrophomonas maltophilia-Augeninfektionen durch beim Hersteller kontaminierte intraokulare Spüllösung. Abstract, p. 241-251. Regensburg: Deutsche Gesellschaft für Hygiene und Mikrobiologie-Tagung.

Berg, G., Knaape, C., Ballin, G. \& Seidel, D. (1994). Biological control of Verticillium dahliae KLEB by naturally occurring rhizosphere bacteria. Arch Phytopathol Dis Prot 29, 249-262.

Berg, G., Marten, P. \& Ballin, G. (1996). Stenotrophomonas maltophilia in the rhizosphere of oilseed rape-occurrence, characterization and interaction with phytopathogenic fungi. Microbiol Res 151, 19-27.

Berg, G., Roskot, N. \& Smalla, K. (1999). Genotypic and phenotypic relationships between clinical and environmental isolates of Stenotrophomonas maltophilia. J Clin Microbiol 37, 3594-3600.

Binks, P. R., Nicklin, S. \& Bruce, N. C. (1995). Degradation of RDX by Stenotrophomonas maltophilia PB1. Appl Environ Microbiol 61, 1813-1322.

Cashion, P., Hodler-Franklin, M. A., McCully, J. \& Franklin, M. (1977). A rapid method for base ratio determination of bacterial DNA. Anal Biochem 81, 461-466. 
Chatelut, M., Dournes, J. L., Chabanon, G. \& Marty, N. (1995). Epidemiological typing of Stenotrophomonas (Xanthomonas) maltophilia by PCR. J Clin Microbiol 33, 912-914.

De Ley, J., Cattoir, H. \& Reynaerts, A. (1970). The quantitative measurement of DNA hybridization from renaturation rates. Eur $J$ Biochem 12, 133-142.

Denton, M. \& Kerr, K. G. (1998). Microbiological and clinical aspects of infections associated with Stenotrophomonas maltophilia. Clin Microbiol Rev 11, 7-80.

Drancourt, M. C., Bollet, C. \& Raoult, D. (1997). Stenotrophomonas africana sp. nov., an opportunistic human pathogen in Africa. Int J Syst Bacteriol 47, 160-163.

Escara, J. F. \& Hutton, J. R. (1980). Thermal stability and renaturation of DNA in dimethylsulphoxide solutions: acceleration of renaturation rate. Biopolymers 19, 1315-1327.

Felsenstein, J. (1992). Phylogenesis from restriction sites: a maximumlikelihood approach. Evolution 46, 159-173.

Finkmann, W., Alterdorf, K., Stackebrandt, E. \& Lipski, A. (2000). Characterization of $\mathrm{N}_{2} \mathrm{O}$-producing Xanthomonas-like isolates from biofilters as Stenotrophomonas nitritireducens sp. nov., Luteimonas mephitis gen. nov., sp. nov. and Pseudoxanthomonas broegbernensis gen. nov. sp. nov. Int J Syst Evol Microbiol 50, 273-282.

Gerner-Smidt, P., Bruun, B., Arpi, M. \& Schmidt, J. (1995). Diversity of nosocomial Xanthomonas maltophilia (Stenotrophomonas maltophilia) as determined by ribotyping. Eur J Clin Microbiol Infect Dis $\mathbf{1 4}$ 137-140.

Hauben, L., Vauterin, L., Swings, J. \& Moore, E. R. B. (1997). Comparison of $16 \mathrm{~S}$ ribosomal DNA sequences of all Xanthomonas species. Int J Syst Bacteriol 47, 328-335.

Hauben, L., Vauterin, L., Moore, E. R. B., Hoste, M. \& Swings, J. (1999). Genomic diversity of the genus Stenotrophomonas. Int $J$ Syst Bacteriol 49, 1749-1760.

Heuer, H., Krsek, M., Baker, P., Smalla, K. \& Wellington, E. M. H. (1997). Analysis of actinomycete communities by specific amplification of genes encoding 16S rRNA and gel-electrophoretic separation in denaturing gradients. Appl Environ Microbiol 63, 3233-3241.

Hugh, R. \& Ryschenko, E. (1961). Pseudomonas maltophilia, an Alcaligenes like species. J Gen Microbiol 26, 123-132.

Huss, V. A. E., Festl, H. \& Schleifer, K. H. (1983). Studies on the spectrometric determination of DNA hybridization from renaturation rates. J Syst Appl Microbiol 4, 184-192.

Ikemoto, S., Suzuki, K., Kaneko, T. \& Komagata, K. (1980). Characterization of strains of Pseudomonas maltophilia which do not require methionine. Int J Syst Bacteriol 30, 437-447.

Jahnke, K.-D. (1992). Basic computer program for evaluation of spectroscopic DNA renaturation data from GILFORD Syst $2600 \mathrm{spec}-$ trometer on a PC/XT/AT type personal computer. J Microbiol Methods 15, 61-73.

Juhnke, M. E. \& Des Jardins, E. (1989). Selective medium for isolation of Xanthomonas maltophilia from soil and rhizosphere environments. Appl Environ Microbiol 55, 747-750.

Kobayashi, D. Y., Gugliemoni, M. \& Clarke, B. B. (1995). Isolation of chitinolytic bacteria Xanthomonas maltophilia and Serratia marcescens as biological control agents for summer patch disease of turf grass. Soil Biol Biochem 27, 1479-1487.

Lane, D. J. (1991). 16S/23S rRNA sequencing. In Nucleic Acid Techniques in Bacterial Systematics, pp. 115-175. Edited by E. Stackebrandt \& M. Goodfellow. Chichester: Wiley.

Mclnroy, J. A. \& Kloepper, J. W. (1995). Survey of indigenous bacterial endophytes from cotton and sweet corn. Plant Soil 173, 337-342.

Mikkat, S., Galinski, E., Minkwitz, A., Berg, G. \& Schoor, A. (2000). Salt adaptation in moderately halotolerant bacteria: characterization of glycosylglycerol-synthethizing isolates from brackish coastal waters and the rhizosphere. Syst Appl Microbiol 23, 31-41.

Miller, K. J. \& Wood, J. M. (1996). Osmoadaptation by rhizosphere bacteria. Annu Rev Microbiol 50, 101-136.

Minkwitz, A. \& Berg, G. (2001). Comparison of antifungal activities and $16 \mathrm{~S}$ ribisomal DNA sequences of clinical and environmental isolates of Stenotrophomonas maltophilia. J Clin Microbiol 39, 139-145.

Moore, E., Krüger, A., Hauben, L., Seal, S., De Baere, R., De Wachter, K., Timmis, K. \& Swings, J. (1997). 16S rRNA gene sequence analyses and inter- and intrageneric relationship of Xanthomonas species and Stenotrophomonas maltophilia. FEMS Microbiol Lett 151, 145-153.

Muyzer, G., de Waal, E. C. \& Uitterlinden, A. G. (1993). Profiling of complex microbial populations by denaturing gradient gel electrophoresis analysis by polymerase chain reaction-amplified genes coding for 16S rRNA. Appl Environ Microbiol 59, 695-700.

Nakayama, T., Homma, Y., Hashidoko, Y., Mitzutani, J. \& Tahara, S. (1999). Possible role of xanthobaccins produced by Stenotrophomonas sp. strain SB-K88 in suppression of sugar beet damping-off disease. Appl Environ Microbiol 65, 4334-4339.

Nesme, X., Vaneechoutte, M., Orso, S., Hoste, B. \& Swings, J. (1995). Diversity and genetic relatedness within genera Xanthomonas and Stenotrophomonas using restriction endonuclease site differences of PCR-amplified 16S rRNA gene. Syst Appl Microbiol 18, 127-135.

Palleroni, N. J. \& Bradbury, J. F. (1993). Stenotrophomonas, a new bacterial genus for Xanthomonas maltophilia (Hugh 1980) Swings et al. 1983. Int J Syst Bacteriol 43, 606-609.

Palleroni, N. J. \& Doudoroff, M. (1972). Some properties and taxonomic subdivisions of the genus Pseudomonas. Annu Rev Phytopathol 10, 73-1000.

Saitou, N. \& Nei, M. (1987). The neighbour-joining method: a new method for reconstructing phylogenetic trees. Mol Biol Evol 4, 406-425. Sasser, M. (1990). Identification of bacteria through fatty acid analysis. In Methods in Phytobacteriology, pp. 199-201. Edited by Z. Klement, K. Rudolph \& D. C. Sands. Budapest: Akademiai Kiado.

Schlungbaum, G., Baudler, H. \& Nausch, G. (1994). Die DarßZingster Boddenkette-ein typisches Flachwasserästuar an der südlichen Ostseeküste. Rostocker Meeresbiologische Beiträge 2, 5-25.

Skerman, V. B. D., McGowan, V. \& Sneath, P. H. A. (1980). Approved lists of bacterial names. Int J Syst Bacteriol 30, 225-420.

Sørensen, J. (1997). The rhizosphere as a habitat for soil microorganisms. In Modern Soil Microbiology, pp. 21-45. Edited by J. D. Van Elsas, J. T. Trevors \& E. M. H. Wellington. New York: Marcel Dekker.

Stackebrandt, E. \& Goebel, B. M. (1994). Taxonomic note: a place for DNA-DNA reassociation and 16S rRNA sequence analysis in the present species definition in bacteriology. Int J Syst Bacteriol 44, 846-849.

Swings, J., de Vos, P., van den Mooter, M. \& De Ley, J. (1983). Transfer of Pseudomonas maltophilia Hugh 1981 to the genus Xanthomonas as Xanthomonas maltophilia (Hugh 1981) comb. nov. Int J Syst Bacteriol 33, 409-413.

Van Den Mooter, M. \& Swings, J. (1990). Numerical analysis of 295 phenotypic features of 266 Xanthomonas strains and related strains and an improved taxonomy of the genus. Int J Syst Bacteriol 40, 48-369.

Van Zyl, E. \& Steyn, P. L. (1992). Reinterpretation of the taxonomic position of Xanthomonas maltophilia and taxonomic criteria in this genus. Int J Syst Bacteriol 42, 193-198.

Wayne, L. G., Brenner, D. J., Colwell, R. R. \& 9 other authors (1987). International Committee on Systematic Bacteriology. Report of the ad hoc committee on reconciliation of approaches to bacterial systematics. Int J Syst Bacteriol 37, 463-464.

Woese, C. R., Gutell, R., Gupta, R. \& Noller, H. F. (1983). Detailed analysis of the higher-order structure of $16 \mathrm{~S}$-like ribosomal ribonucleic acids. Microbiol Rev 47, 621-669. 